\title{
Editorial
}

\section{Grid-Connected and Isolated Renewable Energy Systems}

\author{
Xiaoqiang Guo ${ }^{1, *}$, Minh-Khai Nguyen $\left.{ }^{2} \mathbb{(}\right)$, Mariusz Malinowski ${ }^{3}$ and Elisabetta Tedeschi ${ }^{4}(\mathbb{D}$ \\ 1 Department of Electrical Engineering, Yanshan University, Qinhuangdao 066004, China \\ 2 Department of Electrical and Computer Engineering, Wayne State University, Detroit, MI 48202, USA; \\ nmkhai00@gmail.com \\ 3 Institute of Control and Industrial Electronics, Warsaw University of Technology, 00-662 Warsaw, Poland; \\ malin@isep.pw.edu.pl \\ 4 Department of Electric Power Engineering, Norwegian University of Science and Technology, \\ 7491 Trondheim, Norway; elisabetta.tedeschi@ntnu.no \\ * Correspondence: gxq@ysu.edu.cn
}

check for updates

Citation: Guo, X.; Nguyen, M.-K.; Malinowski, M.; Tedeschi, E. Grid-Connected and Isolated Renewable Energy Systems. Electronics 2021, 10, 2683. https:// doi.org/10.3390/electronics10212683

Received: 24 October 2021

Accepted: 1 November 2021

Published: 3 November 2021

Publisher's Note: MDPI stays neutral with regard to jurisdictional claims in published maps and institutional affiliations.

Copyright: (C) 2021 by the authors Licensee MDPI, Basel, Switzerland. This article is an open access article distributed under the terms and conditions of the Creative Commons Attribution (CC BY) license (https:// creativecommons.org/licenses/by/ $4.0 /)$.
With the rapid progression of renewable energies into grids, grid-connected systems are increasing dramatically around the world. For the efficient and reliable operation of gridconnected systems, many technical challenges should be dealt with, such as model, control, and industrial field applications. At the same time, renewable energy integration has gained momentum in traditionally isolated energy systems, where technical challenges can be even more significant. This special section is dedicated to exploring the state of the art in research and development of grid-connected and isolated energy systems with significant renewable energy penetration, to provide an open opportunity for presentation and discussion of recently advanced technologies. We have accepted a total of five interesting papers that cover important research topics in the domain.

The first paper [1], entitled "Seamless Switching Control Technology for the GridConnected Converter in Micro-Grids", proposes a new seamless switching control technology for a grid-connected converter. It includes a silicon-controlled rectifier forced shutdown control strategy and a three-loop control strategy, which greatly reduces the silicon-controlled rectifier shutdown time and ensures the reliability of local load power supply. In microgrids, distributed energy storage plays a key role in stabilizing the dc bus voltage. The second paper [2], entitled "Bidirectional DC/DC and SOC Drooping Control for DC Microgrid Application", presents an improved SOC power index droop control strategy by communication lines to coordinate the fast and high-precision distribution of load current among multiple energy storage units. The quantification standards of the dc bus fluctuation range and the working range of each converter are further discussed to maximize the stability of the dc bus voltage and grid-connected power fluctuation.

Synchronization is important for grid-connected renewable energy systems. The third paper [3], entitled "Tan-Sun Transformation-Based Phase-Locked Loop in Detection of the Grid Synchronous Signals under Distorted Grid Conditions", proposes a phase-locked loop for the three-phase non-ideal voltages based on the decoupling network composed of two submodules. By selecting the proper decoupling vector by mapping Hilbert space to Euclidean space, the decoupling control for each estimated parameter can be realized. The proposed synchronization technique is improved in terms of the steady and transient performance. In the fourth paper [4], entitled "A New Converter for Non-Isolated PV Systems", the authors propose a new converter for the non-isolated photovoltaic system. It is able to achieve the step-up voltage with four switches only. In addition, the input terminal of the proposed converter is connected to the output negative terminal, and thus the parasitic capacitance is bypassed to eliminate the undesirable leakage current. Aside from that, carried-based modulation is used, and the control structure is simple. This proposal has also been experimentally verified. The fifth paper [5], entitled "AC-DC Converters for Electrolyzer Applications: State of the Art and Future Challenges", presents 
a comprehensive review of currently used AC-DC converters for alkaline and proton exchange membrane electrolyzers in power grid or wind energy conversion systems. A discussion is also provided regarding the future challenges that must face power electronics for green hydrogen production based on renewable energy sources.

The Guest Editorial Board would like to thank the Electronics journal for providing this venue for us to organize this Special Section, the authors for their innovative and valuable contributions, and the reviewers for their prompt and comprehensive feedback and suggestions. Special thanks go to the EiC of Electronics for his leadership and guidance, and also to all the Electronics Editorial team for their excellent and continuous support. We hope that you find this Special Section interesting and useful, serving also as a reference for future work in the field.

Funding: This research received no external funding.

Conflicts of Interest: The authors declare no conflict of interest.

\section{References}

1. Shi, C.; Wei, T.; Sun, Y.; Jia, D.; Li, T. Seamless Switching Control Technology for the Grid-Connected Converter in Micro-Grids. Electronics 2020, 9, 2109. [CrossRef]

2. Zhang, C.; Li, P.; Guo, Y. Bidirectional DC/DC and SOC Drooping Control for DC Microgrid Application. Electronics 2020, 9, 225. [CrossRef]

3. Tan, G.; Zong, C.; Sun, X. Tan-Sun Transformation-Based Phase-Locked Loop in Detection of the Grid Synchronous Signals under Distorted Grid Conditions. Electronics 2020, 9, 674. [CrossRef]

4. Wang, H.; Lu, Z. A New Converter for Non-Isolated PV Systems. Electronics 2021, 10, 1716. [CrossRef]

5. Yodwong, B.; Guilbert, D.; Phattanasak, M.; Kaewmanee, W.; Hinaje, M.; Vitale, G. AC-DC Converters for Electrolyzer Applications: State of the Art and Future Challenges. Electronics 2020, 9, 912. [CrossRef] 